\title{
The Analysis of the Selective Advantage of Internet Finance Development
}

\author{
Dehai Xing ${ }^{1, a}$, Dong Zhu ${ }^{2, b, *}$ and Lifang Luo ${ }^{2, c}$ \\ ${ }^{1}$ China HUARONG Asset Management CO., LTD, Beijing 100033, China \\ ${ }^{2}$ China BlueStar International Chemical Corporation, Beijing 100029, China \\ axingdehai@chamc.com.cn, b zhudong@bluestar.chemchina.com, \\ luolifang@bluestar.chemchina.com
}

\begin{abstract}
The combination of Internet and finance is the emerging trend. Internet technology introduces the innovative spirit into the financial field, the enterprises rely on the internet technology to develop financial products iteratively according to the national situation and industry characteristics, which can enhance enterprise competitiveness. Building evaluation model for the comprehensive competitiveness of enterprises in the development of Internet finance, the enterprise identify the strengths and weaknesses of the development of Internet Finance according to the analysis methods of quantitative and qualitative. It's useful for the enterprise to help to clarify whether to choose Internet finance and how to develop Internet finance to provide decision-making support.
\end{abstract}

Keywords: internet finance; core competence; evaluation model; path selection.

\section{互联网金融发展路径的选择优势分析}

\author{
邢德海 ${ }^{1}$, 朱东 $^{2, *}$, 罗莉芳 ${ }^{2}$
}

'中国华融资产管理股份有限公司, 北京市西城区金融大街8号 100033 中国

${ }^{2}$ 中蓝国际化工有限公司, 北京市朝阳区北三环东路19号 100029 中国

摘 要: 金融拥抱互联网是大势所趋。互联网技术将创新精神植入到金融领域, 企业依靠互 联网技术的迭代研发适合国情和行业特性的金融产品, 提升竞争力。构建企业发展互联网金 融的综合竞争力评价模型, 企业可根据实际情况, 结合定量和定性分析方法, 识别出发展互 联网金融的优势和劣势。为企业是否选择互联网金融以及如何发展互联网金融提供决策支 持。

关键词: 互联网金融; 核心竞争力; 评价模型; 路径选择。

\section{1. 前言}

互联网实现了不同主体之间信息的互联互通。互联网技术为金融中介服务活动实现了便捷 化、自助化。人人都可以成为一个网络终端或结点, 发起或接收金融交易服务。特别是在移 动互联网的背景下, 金融服务不再依赖于地点环境, 可随时随地自助完成, 极大地改善了客 户的服务体验。在互联网蓬勃发展的背景下, 企业是否应该选择进入互联网金融领域, 互联 网金融企业应该如何通过创新增强竞争力, 走出一条适合自身特点的互联网金融之路, 值得 探讨和研究。

\section{2. 互联网金融发展路径}

金融的本质是价值的跨时空转移。互联网与金融的结合使金融业如虎添翼，其原因在于互联 网技术能最有效地处理价值的时空转移。[1]这也是互联网金融核心竞争力的来源。互联网 金融发展揭示出两个基本趋势：互联网企业的金融化和金融企业的互联网化。在这两种趋势 下，互联网金融的发展路径可以大致分为三类：一是 “传统金融企业互联网化” ，如银行网 
银服务就属于此类; 二是 “互联网企业从事金融通道业务” ，如阿里金融推出的余额宝则是 这一领域的代表; 三是 “金融业务结合互联网产生的创新业务” ，如网贷业务就是这类创 新。[2]

\section{3. 互联网金融的核心竞争力来源}

创新是互联网金融的核心竞争力。互联网金融是通过互联网技术的应用和资金融通的本质来 进行跨界融合的。互联网金融的移动性、及时性、透明性和标准化的流程使金融服务超越了 时空限制, 使金融服务的可得性极大的提高。金融市场竞争也日趋白热化, 唯有依托技术创 新、产品创新、服务创新、协作创新, 互联网金融才会有出路。

3.1. 技术创新

金融等于制度加技术加创新。从电报、电话、现在互联网时代, 金融业一直都是技术运用的 领先者。互联网金融对传统金融带来的冲击是因为底层技术贯通, 数据云端存储, 数据存储 技术越来越先进。现在的银行业遇到的最大冲击是因为底层数据还没有贯通, 部门信息是分 割的, 而且中小微的金融服务、屌丝金融服务确实需要加强, 银行业现在大踏步的进行着改 革创新。[3]金融业将会重新焕发它在互联网领域的青春。

3.2. 产品创新

互联网金融企业有自己存在的状态空间，不同的目的使得互联网金融企业存在不同的商业模 式。不同的商业模式构成一个生态圈, 完成同一个功能, 不同功能的生态圈组合起来形成了 一个生态系统。对互联网金融企业来讲一定是以生态系统赢得最后的胜利, 基于生态系统的 产品创新, 综合利用营销网络、服务网络的产品创新, 实现企业自身的良好的状态。[4]只 有通过集体共赢，互联网金融企业才能够赢得生存的状态空间。

\section{3 . 服务创新}

互联网金融企业能够为用户提供私人定制化的产品和服务。对于互联网金融而言，信用是财 富, 服务是价值, 场景是现实, 数据是资产。传统商业逻辑的二八定律在互联网金融行业中 被打破了, 那些原来不被重视的草根金融和碎片金融能够通过互联网金融的技术优势被集结 起来, 被深度开拓, 释放出巨大的商机。因此, 互联网金融企业要重视蓝海市场和长尾市 场, 通过服务创新, 实现真正的普惠金融。[5]随着征信系统的逐步完善, 互联网金融服务 的未来发展将会大有空间，伴随着 “互联网+金融” 的创新、“互联网金融+” 的升级，互联 网金融将使金融服务的 “小微” 变成 “大微”。

3.4. 协作创新

互联网金融是一个分享、协作、自由、平等的行业, 由于准入门槛低和政府监管相对宽松, 互联网金融企业可以比较自由地进入金融市场提供各种产品和服务, 用户也可以比较自由地 进出金融市场选择自己喜欢的产品和服务。这种大环境使得所有互联网金融的参与者都是平 等的, 因此金融企业之间、金融企业与用户之间, 甚至用户与用户之间, 都需要协作与分 享。互联网技术推动了传统金融业变革, 更好的实现了各主体间的优势互补、合作共赢、协 同创新和规范自律，带来了巨大的创新空间。

\section{4. 互联网金融的核心竞争力来源}

互联网精神推崇创新和开放。创新是互联网金融发展的精髓。若想发展互联网金融并获得持 续的竞争力, 企业必须基于互联网思维来着力提升金融服务能力和风险管控能力。提升互联 网金融服务能力, 关键在于产品创新和服务创新; 提升互联网金融风险管控能力, 关键在于 技术创新和协作创新。

\section{1 . 互联网服务能力}

互联网的应用有效解决了金融服务于小额、分散的零售客户的高风险、高成本问题, 企业若 想占据互联网金融的制高点, 需要依托互联网打造的信息平台, 不断提升互联网服务能力, 
借助网络对大量分散主体展开标准化、自助化服务, 使金融服务更趋向于规模经济和范围经 济。互联网金融服务能力的主要影响因素如表-1 所示。

表1 互联网金融服务能力评价因素

\begin{tabular}{|c|c|c|}
\hline 能力类别 & 内容 & 因素 \\
\hline \multirow{4}{*}{ 金融服务优势 } & 金融牌照优势 & $\mathrm{x}_{1}$ \\
\hline & 良好的金融服务优势 & $\mathrm{x}_{2}$ \\
\hline & 资本金充足 & $\mathrm{X}_{3}$ \\
\hline & 利润率客观且合理, 等等 & $\mathrm{X}_{4}$ \\
\hline \multirow{5}{*}{ 产业优势 } & & $\mathrm{x}_{5}$ \\
\hline & 产业服务基础情况, 擅长于某些产业的金融服务和产业服务 & \\
\hline & 在某些金融细分领域，有开展互联网服务的有效经验 & $\mathrm{X}_{6}$ \\
\hline & 具有某些行业或产业的专项信息的综合利用优势，等等 & \\
\hline & & $\mathrm{x}_{7}$ \\
\hline \multirow{4}{*}{ 客户情况 } & 服务对象的年龄群优势 & $\mathrm{X}_{8}$ \\
\hline & 客户粘性 & $\mathrm{X}_{9}$ \\
\hline & 客户对互联网金融服务的接受程度 & $\mathrm{X}_{10}$ \\
\hline & 客户增速及客户满意度情况, 等等 & $\mathrm{x}_{11}$ \\
\hline \multirow{4}{*}{ 资产及人员 } & 轻资产型企业/重资产型企业 & $\mathrm{X}_{12}$ \\
\hline & 总资产规模及资产优良程度 & $\mathrm{x}_{13}$ \\
\hline & 员工学历结构及行业经验丰富程度 & $\mathrm{x}_{14}$ \\
\hline & 信息科技人员占比，等等 & $\mathrm{X}_{15}$ \\
\hline \multirow{3}{*}{ 技术优势 } & 拥有独立的互联网平台 & $\mathrm{X}_{16}$ \\
\hline & 互联网平台的友好性和便捷性优势 & $\mathrm{X}_{17}$ \\
\hline & 平台客户访问量情况, 等等 & $\mathrm{X}_{18}$ \\
\hline 其他 & $\ldots \ldots$ & $\mathrm{X}_{\mathrm{m}}$ \\
\hline
\end{tabular}

4.2. 风险管控能力

不管是在传统的金融模式下，还是互联网金融模式下，风险控制始终是第一位的。互联网金 融除了具有传统金融业经营中的流动性风险、市场风险和利率风险等风险外，还具有业务风 险、技术风险等风险。[6-8]互联网金融风险管控的主要影响因素如表-2 所示。

表 2 互联网金融相关的风险控制能力评价因素

\begin{tabular}{|c|c|c|}
\hline 风险类型 & 内容 & 因素 \\
\hline 流动性风险 & $\begin{array}{c}\text { 流动性风险管理体系是否健全 } \\
\text { 金融产品和技术创新的节奏 } \\
\text { 融资渠道是否畅通 } \\
\text { 资产和负债期限的对比是否合理 }\end{array}$ & $\begin{array}{l}\mathrm{y}_{1} \\
\mathrm{y}_{2} \\
\mathrm{y}_{3} \\
\mathrm{y}_{4}\end{array}$ \\
\hline 市场风险 & $\begin{aligned} & \text { 经济方面: 利率、汇率、通货膨、宏观经济与货币政策、经济 } \text { 周期循环 } \\
& \text { 政治方面: 政权更迭、战争冲突等 } \\
& \text { 社会方面: 提质变革、所有制改造 } \\
&\end{aligned}$ & $\begin{array}{l}\mathrm{y}_{5} \\
\mathrm{y}_{6} \\
\mathrm{y}_{7}\end{array}$ \\
\hline 内部控制与合规风险 & $\begin{array}{c}\text { 良好的内部控制环境的建设: 公司治理、责任机制、激励约束 } \\
\text { 机制、内部控制文化等 } \\
\text { 内部控制措施: 明确划分岗位职责、权限清晰、系统监控的自 } \\
\text { 动化和智能化程度, 核对和监控机制、合规的会计核算和业务 } \\
\text { 记录机制、有效的应急制度等 } \\
\text { 监督与纠正: 对各项业务的例行审查及纠正机制、内部审计机 } \\
\text { 制、外部审计机制、及时的纠错与问责机制等 }\end{array}$ & $\mathrm{y}_{9}$ \\
\hline & & $\mathrm{y}_{10}$ \\
\hline
\end{tabular}




\begin{tabular}{|c|c|c|}
\hline 操作风险 & $\begin{array}{c}\text { 内部欺诈、外部欺诈 } \\
\text { 雇佣关系、客户团系 } \\
\text { 产品及业务操作: 主要涉及网络金融账户的授权使用、网络金 } \\
\text { 融的风险管理系统、网络金融机构和客户间的信息交流、真假 } \\
\text { 电子货币识别等 } \\
\text { 业务中断及系统失灵 } \\
\text { 执行、交易及流程的管理 }\end{array}$ & $\begin{array}{l}\mathrm{y} 1_{1} \\
\mathrm{y}_{12} \\
\mathrm{y}_{13}\end{array}$ \\
\hline 技术风险 & $\begin{array}{c}\text { 技术选择风险：对网络金融而言, 技术选择失误可能失去全部的 } \\
\text { 市场, 甚至失去生存的基础 } \\
\text { 黑客攻击 }\end{array}$ & $\mathrm{y}_{16}$ \\
\hline 模式创新和扭曲风险 & $\begin{array}{c}\text { 互联网金融某种原创的发展模式过于创新或者创新不足, 脱离 } \\
\text { 现实社会经济状况, 最终因发展瓶颈导致失败的风险 }\end{array}$ & $\mathrm{y}_{18}$ \\
\hline 其他 & & $\mathrm{y}_{\mathrm{n}}$ \\
\hline
\end{tabular}

\section{3. 竞争力评价模型}

通过分析互联网金融服务能力的影响因素, 以及风险管控能力的影响因素，设计影响因素评 价函数，构建企业发展互联网金融的综合竞争力评价模型。通过模型定量地测算出企业互联 网金融竞争能力值, 帮助企业识别出发展互联网金融的优势和劣势。

\section{3.1 互联网服务能力综合评价}

互联网综合服务能力因素为 $\mathrm{x}_{\mathrm{i}}$ ，互联网综合服务能力函数为

其中, $\alpha_{i}$ 为综合服务能力评价系数, 应满足

$$
\mathrm{X}=\sum_{i=1}^{m} \alpha_{i} \cdot f\left(x_{i}\right)
$$

$$
\sum_{i=1}^{m} \alpha_{i}=1 \text { 和 } 0 \leq \alpha_{i} \leq 1
$$

通过因子分析法、专家评价法、主成分分析法等方法, 确定每个因素的单独贡献值应满足

所有因素贡献值合计满足

$$
0 \leq f\left(x_{i}\right) \leq 100
$$

$$
0 \leq \sum_{i=1}^{m} f\left(x_{i}\right) \leq 100
$$

4.3.2 风险管控能力综合评价

企业发展互联网金融的风险管控能力影响因素为 $y_{j}$, 企业发展互联网金融的风险管控能力函 数为

$$
\mathrm{Y}=\sum_{j=1}^{n} \beta_{j} \cdot g\left(y_{j}\right)
$$

其中, $\beta_{j}$ 为风险管控能力评价系数, 且应满足

$$
\sum_{j=1}^{n} \beta_{j}=1 \text { 和 } 0 \leq \beta_{j} \leq 1
$$

通过层次分析法、专家评价法、主成分分析法等方法, 确定每个因素的单独贡献值应满足

所有因素贡献值合计满足

$$
0 \leq g\left(y_{j}\right) \leq 100
$$

$$
0 \leq \sum_{j=1}^{n} g\left(y_{j}\right) \leq 100
$$


4. 4.3 企业发展互联网金融的综合竞争力评价

企业发展互联网金融的综合服务能力为 $X(0 \leq X \leq 100)$, 风险管控能力 $Y(0 \leq Y \leq 100)$, 综合竞争能力坐标为

$$
P=(X, Y)
$$

以互联网金融的综合服务能力和风险管控能力构成企业综合竞争力模型，如图-1 所示。区域 $\mathrm{A}$ 表明企业综合竞争力强, 服务能力和风险管控能力都比较强; 区域 $\mathrm{C}$ 表明企业综合竞争力 弱, 服务能力和风险管控能力都比较弱; 区域 B 表明企业的综合服务能力强于风险管控能力; 区域 $\mathrm{D}$ 表明企业的风险管控能力强于综合服务能力。OM线是发展互联网金融的能力平衡线, 表明企业发展互联网金融的综合竞争力强, 且服务能力和风险管控能力比较平衡。企业评价 值越靠近 $\mathrm{OM}$ 线, 且越接近 $\mathrm{M}$ 点时, 表明企业发展互联网金融的竞争力越强。经过综合评价 后，如果企业综合竞争力落入 A 区域，具有发展互联网金融的优势; 如果落在 C 区域，则不 具备发展互联网金融的优势; 如果落入 B、D 区域, 则表明企业能力不平衡, 如果要发展互联 网金融, 需要补强弱势能力。

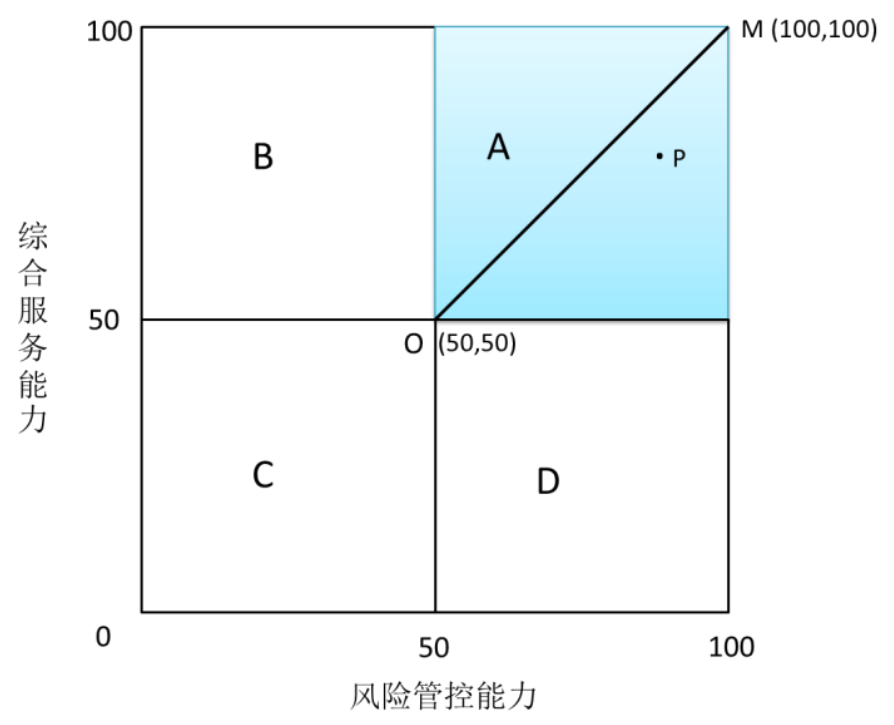

图1 企业发展互联网金融的综合竞争能力模型

\section{5. 互联网金融的路径选择}

经过评价, 竞争力落在 A 区域的企业, 应着力提升基于风险管控和综合服务的创新能力, 在 实现互联网服务与风险管控的平衡发展基础上, 通过技术创新、产品创新、服务创新、协作 创新, 推出安全可靠的特色金融产品和服务。竞争力落在 B 区域的企业, 具有互联网服务优 势, 多为有资质的互联网企业, 可以通过申请金融牌照、收购中小金融机构等方式进军金融 领域。应着力提升互联网金融模式下的风险管控能力, 主要包括市场风险管理、信用风险管 理、风险转移和风险分担。竞争力落在 $\mathrm{C}$ 区域的企业, 具有风险管控的优势, 多为传统金融 机构, 可以通过自建或合作的方式, 利用互联网思想和技术创新盈利模式和改善客户体验。 应着力提升技术创新和互联网平台构建能力，基于互联网的大数据分析和互联互通，建立金 融服务所需的信息充分和信用增强，提升金融服务的规模经济性和范围经济性。竞争力落在 $\mathrm{D}$ 区域的企业, 通常不具有发展互联网金融的明显优势, 可以选择并购、重组、直接投资等 资本方式进入互联网金融领域, 逐渐丰富经验, 稳步提升互联网金融参与和竞争能力, 分享 互联网金融的发展成果。 


\section{References}

[1].SiRu Xiao, KeShuo Xiao. The development trend of the Internet financial and deep influence. Bankers.(2015)No.3.

[2].Information on http://finance.qq.com/. The development of the Internet financial cannot break through the two bottom lines.

[3].Information on http://www.hexun.com/. Technical development makes the unprecedented changes in the financial sector.

[4]. Information on http://www.3ajinrong.com/. Where is the internet era of financial breakthrough direction.

[5]. Information on http://www.3ajinrong.com/. Risk control becomes the key internet financial industry competition in 2015.

[6].Ping Shao. Compliance risk management in commercial bank. China's financial press. (2010) No.5,p.21-46.

[7].LingJuan Zhai. Introduction to the Internet financial mode, advantages and risks. The financial times. (2014) No. 8, p. 45-46

[8].WeiNa Zhang. Internet financial analysis based on the SWOT model. Modern business. (2014) No. 17,p.208-209. 